\title{
Vergleich der diagnostischen Effizienz von handelsüblichen RIA und ELISA Assays und einem Crithidia luciliae Immunfluoreszenztest beim Nachweis von anti-ds-DNA-Antikörpern
}

\author{
Comparison of Diagnostic Efficiency of Different RIA and ELISA Assays and a Crithidia \\ luciliae Immunofluorescence Test for the Detection of anti-ds-DNA Antibodies
}

M. Blazek, E. Werle, W. Fiehn

Zentrallabor der Medizinischen Klinik und Poliklinik,der Universität Heidelberg

\begin{abstract}
Zusammenfassung:
Der Nachweis von anti-ds-DNA-Antikörpern ist eines der 1982 von der American Rheumatism Association aufgestellten diagnostischen Kriterien für den systemischen Lupus erythematodes (SLE). In dieser Arbeit wurden einige der auf dem deutschen Markt zur Verfügung stehenden Assays - zwei Radioimmunoassays, vier "Enzyme Linked Immunosorbent Assays" und ein Crithidia luciliae Immunfluoreszenztest - im Hinblick auf ihre diagnostische Effizienz untersucht. Das Patientenkollektiv bestand aus 35 Patienten mit überwiegend rheumatischen Krankheitsbildern aus dem Einzugsgebiet der Universität Heidelberg. Trotz ausgiebiger klinischer und laborchemischer Untersuchungen kann man in einigen Fällen nicht ausschließen, daß die definitive Diagnose im weiteren Verlauf der Erkrankung anders lauten wird. In der vorliegenden Untersuchung wurde überprüft, (1) inwieweit die verschiedenen Assays übereinstimmende Ergebnisse liefern und (2) wie die diagnostische Effizienz bezüglich der Differentialdiagnose SLE bei einem 'vorselektionierten Kollektiv ist. Die Übereinstimmung zwischen den Assays betrug 60-80\% und die Korrelationskoeffizienten lagen zwischen 0,33 und 0,99. Bei einer SLE-Prävalenz von 0,47 im untersuchten Kollektiv errechnete sich bei einer Sensitivität zwischen 0,63-1,0 und einer Spezifität von 0,21-0,68 für alle untersuchten Assays eine diagnostische Effizienz von 0,51-0,66. Die Ergebnisse differieren auch bei standardisierten (WHO, Wo 80) Testsystemen erheblich, da diese anti-ds-DNA-Antikörper unterschiedlicher Aviditäten und Klassen erfassen. Eine intraindividuelle Verlaufskontrolle sollte deshalb nur innerhalb eines Testsystems erfolgen. Wie jedoch die Ergebnisse im einzelnen zeigen, ist die Bestimmung von anti-ds-DNA-Antikörpern nur dann sinnvoll, wenn sie mit der klinischen Diagnostik und Erfahrung kombiniert wird.
\end{abstract}

Schlüsse/wörter:

Anti-ds-DNA-Antikörper - ds-DNA-ELISA - ds-DNA-RIA - Lupus erythematodes - Crithidia luciliae

\begin{abstract}
Summary:
One of the diagnostic criteria for systemic lupus erythematosus (SLE) according to American Rheumatism Association (1982) is the positive test for anti-ds-DNA-antibodies. We have investigated the diagnostic efficiency of seven commercially available anti-ds-DNA-kits, namely two radioimmunoassays, four enzyme linked immunosorbent assays and one Crithidia luciliae immunofluorescience test. 35 sera of patients with mainly rheumatologic diseases sent to the Central Laboratory of the University of Heidelberg were tested.

By some patients one cannot exclude the possibility of the preliminary diagnosis changing during the course of the illness. In this work we analyzed (1) whether the results of the different assays are comparable and (2) the diagnostic efficiency in regard to the differential diagnosis SLE by selected patients. The agreement between the assays was $60-80 \%$ with correlation coefficients between 0.33 and 0.99 . In our patient group SLE prevalence was 0.47 . The sensitivity ranged from $0.63-1.0$ and the specificity from $0.21-0.68$ resulting in a diagnostic efficiency of 0.51-0.66 for all assays under investigation. The results differ even though the assays are standardized (W080) because of the detection of different avidities and classes of autoantibodies. Therefore, the follow-up should be done with one diagnostic system. Anti-ds-DNA-assays are diagnostically useful orily when combined with clinical diagnosis and experience.
\end{abstract}

Keywords:

Anti-ds-DNA-antibodies - ds-DNA-ELISA - ds-DNA-RIA - systemic lupus erythematosus - Crithidia luciliae 


\section{Diagnostik in [Deutschland hat eúnen gutten Namen: Behring}

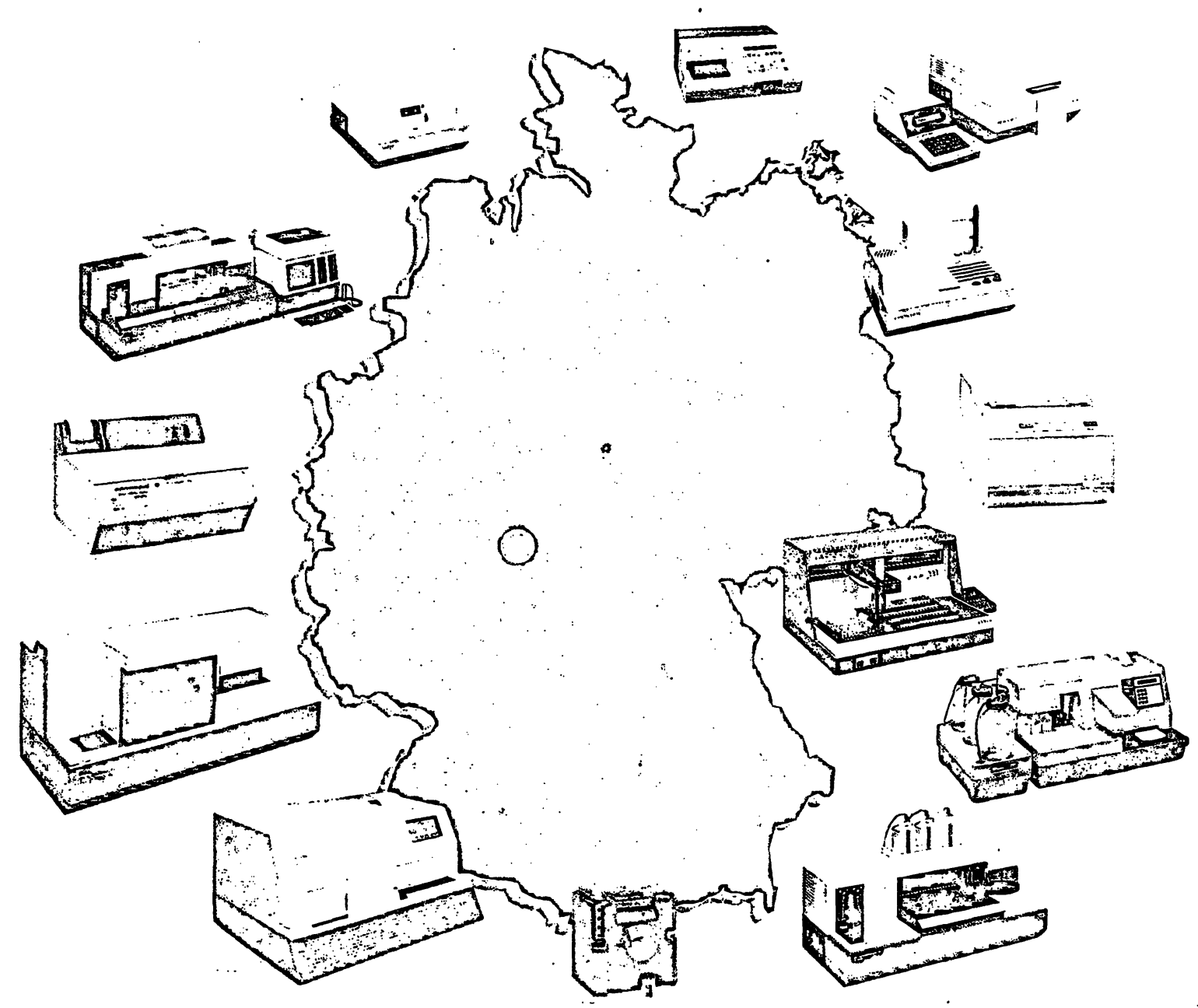

Behring bietet Ihnen ein umfassendes DiagnostikaProgramm. Von qualitativen Screening-Testen für die arztliche Praxis, die leicht zu handhaben und schnell abzulesen sind, bis zu hochspezifischen automatisierten
Systemen für die quantitative Laboratoriumsdiagnostik.

Behring arbeitet intensiv an neuen Entwicklungen, die Ihre Probleme immer intelligenter und exakter lösen.
Sprechen Sie mit uns über

Proteindiagnostik

Gerinnungsdiagnostik

Mikrobiologie

Tumordiagnostik
Sitz des Unternehmens

Zentrale für Deutschland
Behringwerke AG

Postfach 1140, 3550 Marburg/Lahn

Behringwerke AG

Med. Information und Verkauf

Postfach 800280

6230 Frankfurt/M. 80
BEHRING $S_{1} d_{2} h_{i n g}$ 


\section{Steureralienst iürr den Arzi}

Die für den Arzt einschlägigen Urteile finden Sie - nach Stichworten geordnet - in dem Loseblattwerk von Obersteuerrat Robert Linden.

Das Werk enthält u. a. die statistischen Kostensätze der Ärzte aller Fachrichtungen sowie Testbögen, die eine genaue Kostenanalyse der Praxis ermöglichen. Der Rationalisierung Ihrer Praxis dient das ausführliche „ABC der abzugsfähigen Ausgaben bei der Einkommensteuer".

\section{Hand aufs Herz}

* Verschenken Sie nicht auch Jahr für Jahr viel Geld an das Finanzamt?

* Nehmen Sie alle legalen Steuerminderungsmöglichkeiten in Anspruch?

* Stellen Sie rechtzeitig die notwendigen Anträge?

* Haben Sie Zeit und Gelegenheit, sich über Ihre berufsspezifischen Steuerfragen in den Steuerfachzeitschriften zu orientieren?

* Verlassen Sie sich ganz auf Ihren Berater?

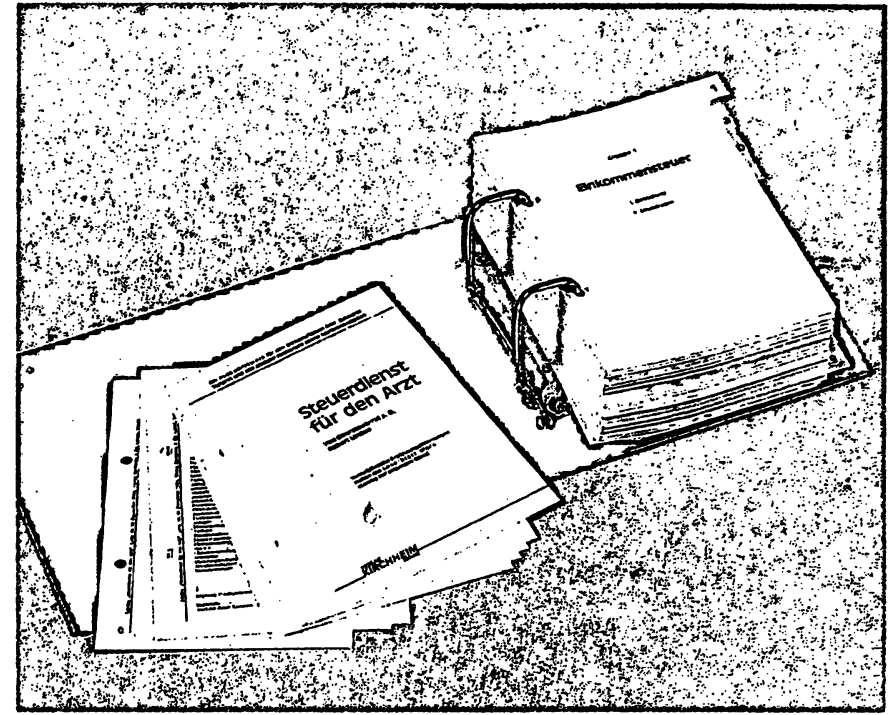

* Haben Sie schon einmal einen Praxiskostentest gemacht?

* Wissen Sie, ob Sie mehr oder weniger als Ihre vergleichbaren Kollegen verdienen?

\section{VERLAC}

KIRCHHEIMPostrach 2524,6500 Mainz1 MAINZ

Hiermit bestelle ich ein Grundwerk „Steuerdienst für den Arzt" zum Preis von 79,80 DM und die künftig vierteljährlich erscheinenden Ergänzungslieferungen zum Seitenpreis von $-, 37 \mathrm{DM}$

Sie garantieren mir, daß ich diese Bestellung binnen einer Frist von einer Woche schriftlich widerrufen kann. Der Widerruf ist an den Verlag Kirchheim, Postfach 25 24, 6500 Mainz, zu richten. Zur Wahrung der Frist genügt die rechtzeitige Absendung des Widerrufs.

Datum/Unterschirift:
Anschrift:

Name:

Straße:

PLZ/Ort: 


\section{Einleitung}

Der systemische Lupus erythematodes (SLE) zählt neben der rheumatoiden Arthritis, der Sklerodermie, der Polymyositis und der Periarteriitis nodosa zu den Kollagenosen im engeren Sinne. Die Inzidenz beträgt. etwa 5 Fälle/ 100000 Einwohner/Jahr, Frauen, sind 6- bis 10mal häufiger betroffen als Männer. Die Erkrankung beginnt meist im 2. bis 3. Lebensjahrzehnt, doch kann sie in fast jedem Alter manifest werden (7).

Ein schleichender Krankheitsbeginn mit Fieber und Gelenkschmerzen wird meist als rheumatoide Arthritis verkannt. Erst das Hinzukommen von charakteristischen Symptomen ermöglicht die endgültige Diagnose des SLE.

Im Jahre 1982 wurden von der American Rheumatism Association (ARA) 11 diagnostische Kriterien vorgeschlagen, von denen im 'Falle eines Lupus erythematodes visceralis vier oder mehr zutreffen sollten. $\mathrm{Zu}$ diesen gehören das für diese Erkrankung so charakteristische Schmetterlingserythem, discoide Läsionen, Photosensibilität, orale oder nasopharyngeale Ulcera, nichterosive Arthritis mit Beteiligung von mindestens zwei peripheren Gelenken, Serositis, die sich als Pleuritis oder Perikarditis manifestieren kann, neurologische Symptome in Form von Krampfanfällen oder Psychosen, hämatologische $\mathrm{Be}$ funde wie hämolytische Anämie mit Retikulozytose, Leuko-, Lympho- und Thrombocytopenie. Weitere labordiagnostische Kriterien sind der Nachweis von antinukleären Antikörpern mit einem Titer $>1: 160$ sowie der Nachweis des LE-Zell-Phänomens, von anti-ds-DNA-Antikörpern, anti-Sm-Antikörpern und ein falsch positiver Syphilistest über mindestens 6 Monate (20).

Von diesen Laborparametern sind sicherlich die folgenden drei am sinnvollsten:

Der Nachweis (1) von ANA mittels IFT mit einer hohen Sensitivität, aber einer nur mäßigen Spezifität, (2) von anti-ds-DNA-AK mittels RIA und (3) von anti-Sm-AK mittels etablierter immundiagnostischer Techniken wie Ouchterlony-Doppelimmundiffusion oder Überwanderungselektrophorese. Beide letztgenannten Verfahren weisen eine hohe Spezifität, aber eine mäßige Sensitivität auf. Der Nachweis von anti-ds-DNA-Antikörpern und anti-Sm-Antikörpern trägt sicherlich zur Untermauerung der Diagnose bei, da es manchmal klinisch recht schwer zu beurteilende, sich nicht gegenseitig ausschließende und überlappende Krankheitsbilder gibt. Die in Frage kommenden Antikörper sind nicht in allen Fällen und teilweise auch nur vorübergehend nachweisbar (7). Wertvoll sind zur Verlaufsbeurteilung die anti-ds-DNA-Antikörper, da insbesondere die Antikörper der IgG-Klasse auch als
Abkürzungen:
ANA Antinukleäre Antikörper
CLIF Crithidia luciliae Immunfluoreszenztest
dsDNA doppelsträngige DNA
ssDNA einzelsträngige DNA
ELISA Enzyme linked immunosorbent assay
RIA Radioimmunoassay
ARA American Rheumatism Association
IFT Indirekter Immunfluoreszenz-Test
FITC Fluoreszeinisothiozyanat
SLE Systemischer Lupus Erythematodes

ein Aktivitätsparameter für den SLE angesehen werden (17).

Fụ̈r die Bestimmung der anti-ds-DNA-Antikörper gibt es auf dem Markt eine Vielzahl von verschiedenen Assays, dehen teilweise unterschiedliche Prinzipien zugrunde liegen. Einige von diesen werden im folgenden im Hinblick auf ihre Spezifität, Sensitivität und Durchführbarkeit näher dargestellt und miteinander verglichen.

\section{Material und Methoden}

Assays

Für die Bestimmung von anti-ds-DNA-Antikörpern wurden folgende im Handel erhältliche Assays verwendet:

R-NEN: Anti-Doppelstrang-DNA-RIA (Anti-ds-DNA ${ }^{1251} \mathrm{Ra}$ diobinding Assay Kit) von Du Pont de Nemours $\mathrm{GmbH}$, NEN Division, Daimlerstraße 23, 6072 Dreieich 4

R-AB: Anti-Doppelstrang-DNA-RIA von Amersham-Buchler GmbH \& Co KG, Gieselweg 1, 3300 Braunschweig

CLIF: Crithidia luciliae Immunfluoreszenztest von MeDiCa Medical Diagnostics California, 2382 Camino Vida Roble Carlsbad CA 92009, im Vertrieb von BioMedical Diagnostics GmbH, Max-Planck-Ring 41, 6200 Wiesbaden-Delkenheim

E-BHT: ds-DNA-ELISA von BioHyTech, 10 Dov Friedman St., Ramat Gan, 52503 Israel, im Vertrieb von Flow Laboratories $\mathrm{GmbH}$, Mühlgrabenstraße 10,5309 Meckenheim

E-ELI: ds-DNA-ELISA von Elias Medizintechnik $\mathrm{GmbH}_{\text {, }}$ Obere Hardtstraße 18, 7800 Freiburg

E-PRO: ds-DNA-ELISA von Progen Biotechnik $\mathrm{GmbH}$, im Neuenheimer Feld 519, 6900 Heidelberg

E-WA: ds-DNA-ELISA von Walker Diagnostics, Cambridge Life Sciences plc, Angel Drove Ely, Cambridgeshire CB7 4DT England, im Vertrieb von Byk Sangtec Diagnostica, Von-Hevesy-Straße, 6057 Dietzenbach 2

ANA: Antinukleäre Antikörper, bestimmt mittels indirektem Immunfluoreszenztest auf HEp-2-Zellen von MeDiCa Medical Diagnostics California, 2382 Camino Vida Roble, Carlsbad CA 92009, im Vertrieb von BioMedical Diagnostics GmbH, Max-Planck-Ring 41, 6200 Wiesbaden-Delkenheim

Mikroskopiereinrichtung: Die Mikroskopiereinrichtung bestand aus einem Olympus BH2-Mikroskop mit Epilumineszenz. Gearbeitet wurde mit einer Blauanregung für FITC bei einer Halbwertbreite von 500 bis $780 \mathrm{~nm}$ mit definierten Erreger- und Sperrfiltern. Die Benutzungszeit der HBO 100-Lampe betrug weniger als 200 Stunden. Die Beurteilung der ANA und CLIF erfolgte mit einer 400bzw. 1000fachen Vergrößerung unter Verwendung folgender Objektive: S Plan 40 von Olympus und PL Fluotar 100 von Zeiss.

\section{Patientenkollektiv}

Für die Untersuchungen wurden Patientenproben verwendet, diel überwiegend von den Stationen und den rheumatologischen Ambulanzen der Medizinischen Klinik und Poliklinik sowie von der Haut-, Frauen- und Neurologischen Klinik der Universität Heidelberg eingesandt wurden. Bewußt wurden Seren von 35 Problempatienten ausgewählt, die sich mit Verdacht auf oder zum Ausschluß von rheumatischen Erkrankungen vorstellten. Dieses selektierte Kollektiv umfaßte 16 Patienten mit der Hauptdiagnose SLE, 4 mit Rheumatoider.Arthritis, 2 mit Sjögren Syndrom, 4 mit Mixed Connective Tissue Dis- 
ease, 1 mit Sklerodermie, 6 nichtrheumatisch Erkrankte und je 1 Patienten mit parainfektiöser Arthritis und Oligoarthritis.

\section{Testcharakteristika}

\section{RIA-Prinzip}

Den anti-ds-DNA-RIAs liegt die sogenannte Farr-Technik zugrunde. Diese besteht in der Inkubation von Humanseren bei $37^{\circ} \mathrm{C}$ mit ${ }^{125} \mathrm{Jod}$-markierter ds-DNA, wobei anschließend die gebildeten ds-DNA-Antigen-Antikörperkomplexe mit einem Präzipitationsreagenz gefällt werden, während die ungebundene ds-DNA in Lösung bleibt. Die anti-ds-DNA-Antikörperkonzentration im Serum ist direkt proportional zur Radioaktivität im Präzipitat und wird mittels einer Standardkurve ermittelt.

\section{Durchführung von R-AB und R-NEN}

Bei den beiden auf dem deutschen Markt zur Verfügung stehenden ds-DNA-RIAs liegt der obere Meßbereich bei $100 \mathrm{U} / \mathrm{ml}$. Die für 100 Bestimmungen eingesetzte Radioaktivität beträgt bei NEN/Du Pont $10 \mu \mathrm{Ci}(370 \mathrm{kBq})$, bei Amersham-Buchler $4 \mu \mathrm{Ci}$. Die Standardisierung wurde bei R-NEN mit dem U.S. National Reference Serum ANA Human Serum No. 1. (catalog no. IS2072, lot 82-007) vorgenommen, wobei dieses willkürlich mit $115 \mathrm{U} / \mathrm{ml}$ festgelegt wurde. Die Standards des R-AB wurden an der Ersten Internationalen Standardpräparation (Wo 80) für dsDNA-Antikörper kalibriert, weshalb die Werte in internationalen Einheiten (IU/mI) angegeben werden.

Das eingesetzte Probenvolumen beträgt $10 \mu$ l bei R-NEN, $25 \mu$ l bei R-AB. Der wichtigste Unterschied zwischen den beiden besteht in der Verwendung einer nativen doppelsträngigen ${ }^{125} \mathrm{I}$-markierten DNA bei R-AB, die aus einem synthetisch hergestellten Plasmid stammt. Die spezifische Kopplung des ${ }^{125} /$ an die Enden der rekombinanten ds-DNA soll eine minimale Radiolyse der ds-DNA gewährleisten und eine gute Reproduzierbarkeit von Charge zu Charge garantieren. Im R-AB wird Ammoniumsulfat als Präzipitationsreagenz verwendet, bei R-NEN liegen keine Angaben vor. Ein Vorteil des R-AB liegt sicherlich in der einstündigen Inkubationszeit gegenüber der zweistündigen bei R-NEN. Die Normalbereiche betragen $<1,0 \mathrm{U} / \mathrm{ml}$ bei R-NEN bzw. $<7,0 \mathrm{IU} / \mathrm{ml}$ bei R-AB. Kontrollseren sind für beide Tests erhältlich.

\section{ELISA-Prinzip:}

Die mit ds-DNA beschichtete Festphase wird mit der zu untersuchenden Probe inkubiert. Nach der Antigen-Antikörper-Reaktion erfolgt das Waschen der Festphase und Inkubation mit einem Enzym-markierten Zweitantikörper, der gegen die humanen Antikörper gerichtet ist. Nach Waschen, Substratzugabe und Inkubation wird photometrisch gemessen. Da alle untersuchten ELISAs nach dem Sandwich-Prinzip aufgebaut sind, nimmt mit Steigender Analytkonzentration auch die Extinktion zu.

\section{BioHyTech anti-ds-DNA-Antikörper ELISA}

Als Festphase dient eine mit ds-DNA beschichtete Mikrotiterplatte. Das zugegebene Konjugat ist trivalent (anti$\lg G,-\lg A,-\lg M)$. Als Substrat für die Alkalische Phosphatase wird Para-Nitrophenolphosphat (PNPP) verwendet, die Photometrie erfolgt bei $402 \mathrm{~nm}$. Die Inkubationszeiten betragen 90 Minuten. Von uns als nachteilig empfunden wurde das Vorhandensein von nur drei Standards . (192, 359 und $895 \mathrm{U} / \mathrm{ml})$ und eine willkürliche Kalibration des Assays unter Verwendung von internen SLE Kontrollseren. Weder Kontrollen (positiv, negativ) noch Angaben über einen Normbereich lagen bei. Der von uns benutzte
Grenzwert von $160 \mathrm{U} / \mathrm{ml}$ wurde aufgrund von ROC-Kurve ermittelt (Abb. 2). Bei E-BHT sind nicht alle 16, sondern nur 13 Patienten mit SLE untersucht worden.

\section{Progen anti-ds-DNA-Antikörper ELISA}

Die Inkubation der Proben erfolgt in Mikrotiterplatten (wahlweise sind Strips erhältlich), beschichtet mit aus Kalbsthymus gewonnener ds-DNA. Verwendet wird AntiHumanimmunglobulin G-Peroxidase-Konjugat mit 1,2Phenylendiamin als Substrat und ein an zwei WHO-Referenzpräparationen (Wo 80 und "temporary reference preparations: human IgG subclass proteins/WHO-lgG-Subcomittee") abgeglichener Humanstandard. Nach einer zweistündigen Inkubationszeit erfolgt die Photometrie bei $492 \mathrm{~nm}$. Jeweils eine positive und negative Kontrolle sind beigefügt. Der Test ist laut Herstellerangaben zwischen 25 bis $50 \mathrm{lU} / \mathrm{ml}$ schwach positiv, bei mehr als $50 \mathrm{IU} /$ $\mathrm{ml}$ deutlich positiv.

\section{Elias anti-ds-DNA-Antikörper ELISA}

Der Assay arbeitet mit insgesamt drei verschiedenen Mikrotiterplatten und einer mit dem ds-DNA-Antigen beschichteten Pinplatte. Beim Eintauchen der Pinplatte in die Mikrotiterplatte mit sich darin befindlichen Patientenproben kommt es zur Bildung von ds-DNA-Antigen-Antikörper-Komplexen. In der zweiten Mikrotiterplatte verbinden sich diese mit einem Meerrettich-Peroxidase-markierten Anti-lgG-AK zu einem Sandwich. Die Chromogenbildung nach Substratzugabe wird in der dritten Mikrotiterplatte nach 70 Minuten Gesamtinkubationszeit bei 492 $\mathrm{nm}$ photometrisch erfaßt. Der Test ist ebenfalls WHO (Wo $80)$ standardisiert, eine interne Kontrolle ist vorhanden. Die obere Normgrenze beträgt $40 \mathrm{IU} / \mathrm{ml}$.

\section{Walker anti-ds-DNA-Antikörper ELISA}

Der Assay auf Pinprinzipbasis erfaßt Antikörper der lgGund IgM-Spezifität. Als Substrat für die Peroxidase dient o-Phenylendiamin- $\mathrm{HCl}$. Die Inkubationszeiten betragen 40 Minuten. Die Kalibration erfolgte gegen die WHO Referenz Wo/80. Kontrollserum ist erhältlich. Die obere Normgrenze liegt bei $50 \mathrm{IU} / \mathrm{ml}$.

\section{Crithidia luciliae Test}

Crithidia luciliae ist ein Flagellat, dessen Kinetoplast native, doppelsträngige DNA enthält. Die Inkubation der mit Crithidia luciliae beschichteten Objektträger erfolgt eine halbe Stunde lang mit 1:10 verdünnten Patientenseren, nach dreimaligem Waschen dann mit polyvalentem Konjugat. Bei denjenigen Seren, die sich als positiv auf dem Crithidia luciliae Substrat erwiesen haben, wurde der Test nach einer Behandlung der Objektträger mit $0.1 \mathrm{M}$ $\mathrm{HCl}$ wiederholt, um eventuell interferierende Antigene zu eliminieren $(5,8,13)$,

Die in dieser Arbeit erwähnten Assays wurden uns freundlicherweise von den angegebenen Firmen kostenlos zur Verfügung gestellt. Die Proben wurden bis zum Untersuchungsdatum bei $-20^{\circ} \mathrm{C}$ portioniert eingefroren. Die Analysen wurden unter Berücksichtigung des Verfallzeitraumes der Kits entsprechend den Angaben der Hersteller durchgeführt.

\section{Statistik:}

Angegeben sind der Pearson Korrelationskoeffizient $r$ als Maß für den Zusammenhang zwischen zwei Parametern, das Signifikanzniveau $P$ wurde auf $5 \%$ festgesetzt. Die Berechnungen erfolgten mit dem Programm „Methodenvergleich" (Version 1.10, Boehringer Mannheim GmbH, FRG), das freundlicherweise von Dr. Bablok zur Verfügung 


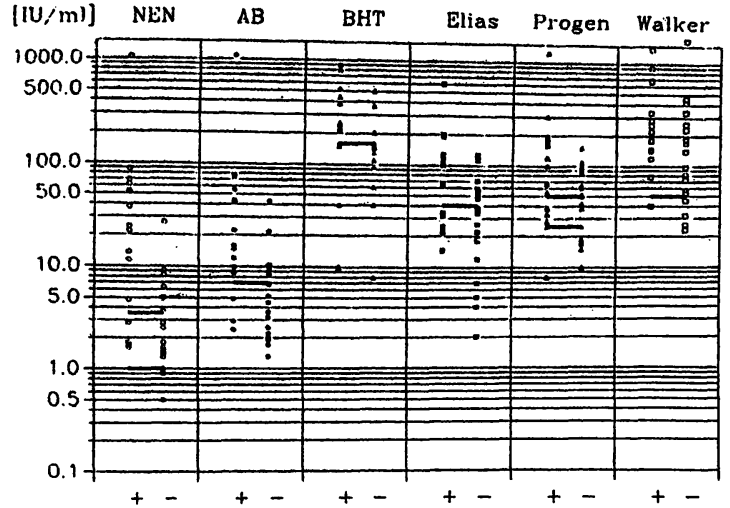

SLE

Abb. 1: Darstellung der anti-ds-DNA-Antikörper Testergebnisse und Grenzwerte (-) von 2 RIAs (NEN, AB) und 4 ELISAs (BHT, Elias, Progen, Walker) in bezug auf die klinische Diagnose Lupus erythematodes (SLE):

gestellt wurde. Die Berechnung der Ausgleichsgeraden erfolgte nach Prüfung auf Abweichung von der Linearität (Cusum-Test, Kolmogorov-Smirnov) nach dem Verfahren nach Passing/Bablok (1). Die statistischen Kenngrößen (Tab. 4) wurden auf der Grundlage der klinischen Diagnose zum Zeitpunkt der Untersuchung berechnet.

Die statistischen Parameter (Tab. 4) wurden nach folgenden Formeln berechnet (Tp = Test positiv, $T n=$ Test negativ, $L p=S L E, L n=$ klinisch kein SLE, TpLp = Test positiv und SLE positiv, $T n L n=$ Test negativ und SLE negativ): Prävalenz $=L p /(L p+L n)$; Sensitivität $=T p / L p$; Spezifität $=T n / L n$; diagnostische Effizienz $=(T p L p+T n L n) /$ $(L p+L n)$; positiver Vorhersagewert $=T p L p / T p ;$ negativer Vorhersagewert $=\mathrm{TnLn} / \mathrm{Tn}$.

\section{Ergebnisse}

In Abbildung 1 sind die mit zwei RIAs und vier ELISAs ermittelten anti-ds-DNA-Antikörperspiegel von 35 Patienten dargestellt. Aus Tabelle 3 ist ersichtlich, bei welcher Hauptdiagnose die untersuchten Patienten ein positives Testergebnis bei den vier ELISAs, den beiden RIAs, im Crithidia luciliae Test und im ANA-Immunfluoreszenztest auf Hep2-Zellen aufwiesen. Ob es sich z. T. um falsch positive Testergebnisse oder um den richtigen Nachweis von anti-ds-DNA-Antikörpern handelt, kann man nur indirekt mittels der Testübereinstimmungen (Tab. 2) abschätzen. Der Amersham RIA und der NEN RIA mit einem Grenzwert von 3,5 U/ml stimmen in $89 \%$ der Ergebnisse überein und sind sehr hoch korreliert $(r=0,99$; tau $=$ 0,$73 ; R-A B=1,09+1,55 \times R-N{ }^{*}$. Der ELISA von Progen

Tab. 1: Ergebnisse der RIA-, ELISA- und CLIF-Untersuchung auf anti-ds-DNA-Autoantikörper bei 35 Patienten (Hauptdiagnosen $s$. Patientenkollektiv).

\begin{tabular}{lccc}
\hline Assay & Grenzwert & $\begin{array}{c}\text { positiver Test/ } \\
\text { klinisch SLE }\end{array}$ & $\begin{array}{c}\text { positiver Test/ } \\
\text { klinisch kein SLE }\end{array}$ \\
\hline CLIF & - & $10 / 16$ & $8 / 19$ \\
R-AB & $\geq 7,0$ & $13 / 16$ & $7 / 19$ \\
R-NEN & $\geq 1,0$ & $16 / 16$ & $17 / 19$ \\
R-NE* & $\geq 3,5$ & $12 / 16$ & $8 / 19$ \\
E-ELI & $\geq 40$ & $10 / 16$ & $8 / 19$ \\
E-BHT & $\geq 160$ & $10 / 13$ & $9 / 19$ \\
E-PRO & $\geq 25$ & $15 / 16$ & $14 / 19$ \\
E-PR* & $\geq 50$ & $11 / 16$ & $9 / 19$ \\
E-WA & $\geq 50$ & $15 / 16$ & $14 / 19$ \\
ANA & $\geq 1: 40$ & $16 / 16$ & $15 / 19$ \\
\hline
\end{tabular}
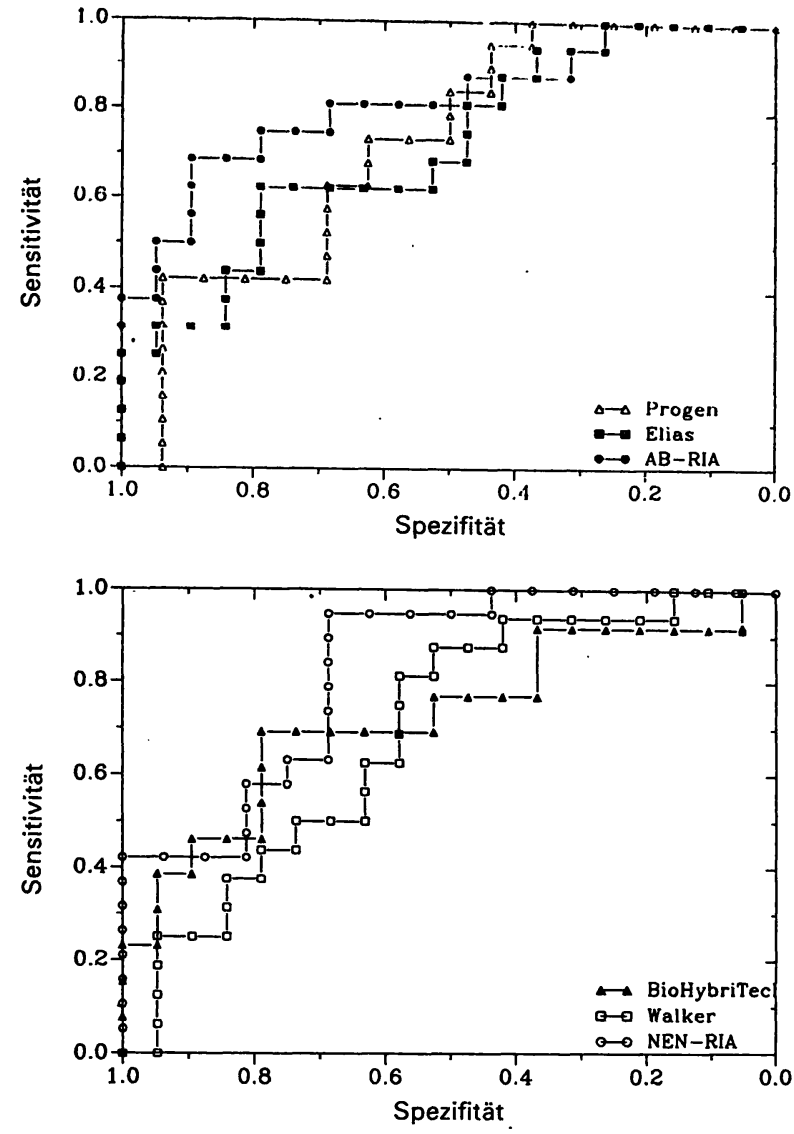

Abb. 2: Spezifitäts-Sensitivitätsdiagramme von anti-ds-DNA-Testsystemen (Abk. s. Material und Methoden).

mit einem vom Hersteller angegebenen Grenzwert von $50 \mathrm{lU} / \mathrm{ml}$ liefert in $83 \%$ die gleichen Ergebnisse wie der ELISA von Elias und der von Walker (Tab. 2). Die Korrelationskoeffizienten der linearen Regression sind in Tabelle 2 dargestellt, wobei jedoch die starke Beeinflußbarkeit der Berechnung durch Extremwerte die Aussagekraft einschränkt. Die beiden nach der WHO-Referenz (Wo 80) standardisierten ELISAs von Progen und Elias, die jeweils IgG-Antikörper erfassen, sind sehr hoch linear korreliert $(r=0,95$; tau $=0,68)$ mit folgender Ausgleichsgeraden: E-PRO $=1,93+1,15 \times$ E-ELI (1). Der ebenfalls WHO standardisierte Test yon Walker, der allerdings zusätzlich IgMAntikörper gegen ds-DNA erfaßt, korreliert wesentlich geringer mit E-PRO und E-ELI (Tab. 2) und liefert deutlich höhere Ergebnisse (E-WA $=-17,08+3,27 \times$ E-PRO; E-

Tab. 2: Übereinstimmungen und Korrelationen der verschiedenen Nachweismethoden von anti-ds-DNA-Antikörpern

Übereinstimmung (\%) lineare Korrelationskoeffizienten $r$

( $* P<0,05 ;+P<0,05$,

_.: Nicht linear im Cusum-Test)

\begin{tabular}{|c|c|c|c|c|c|c|c|c|c|c|c|}
\hline & & & & & & & & & & & \\
\hline R-NEN & 66 & 60 & & & & R-AB & E-BHT & E-ELI & E.PRO & E-WA & \\
\hline R-AB & 89 & 60 & 66 & & & $0,99 *$ & $0,52^{*}$ & $0,89 *$ & $0,97^{*}$ & 0,33 & R-NEN \\
\hline E-BHT & 63 & 56 & 63 & 69 & & & $0,52^{*}$ & $0,89^{*}$ & $0,96^{*}$ & 0,33 & R.AB \\
\hline E-ELI & 66 & 66 & 54 & 71 & 69 & & & $0,70^{*}$ & $0,61^{*}$ & $\overline{0,55^{*}}$ & E-BHT \\
\hline E-PRO & 69 & 69 & 80 & 69 & 66 & 69 & & & $0,95^{*}$ & $0,55^{*}$ & E-ELI \\
\hline E-PR* & 60 & $\pi$ & 54 & 66 & 69 & 83 & 74 & & & $0,45^{+}$ & E.PRO \\
\hline E-WA & $\begin{array}{c}69 \\
\text { R.NE* }\end{array}$ & 74 & $\begin{array}{c}74 \\
\text { R-NEN }\end{array}$ & $\begin{array}{c}74 \\
\text { R-AB }\end{array}$ & $\begin{array}{c}66 \\
\text { E-BHT }\end{array}$ & $\begin{array}{c}69 \\
\text { E-ELI }\end{array}$ & $\begin{array}{c}83 \\
\text { E-PRO }\end{array}$ & $\begin{array}{c}74 \\
\text { E.PR* }\end{array}$ & & & \\
\hline
\end{tabular}


Tab. 3: Positive Ergebnisse von ds-DNA-Assays und ANA im Vergleich zur klinischen Diagnose (Grenzwerte s. Tab. 1).

\begin{tabular}{lcccccccc}
\hline Diag. & SLE & RA & SS & MCTD & SCL. & $\begin{array}{c}\text { para- } \\
\text { infekt. }\end{array}$ & $\begin{array}{c}\text { nicht } \\
\text { rheum. }\end{array}$ & $\begin{array}{c}\text { Oligo- } \\
\text { arthri. }\end{array}$ \\
\hline CLIF & $10 / 16$ & $2 / 4$ & $2 / 2$ & $1 / 4$ & $1 / 1$ & $1 / 1$ & $1 / 6$ & $0 / 1$ \\
R-AB & $13 / 16$ & $1 / 4$ & $1 / 2$ & $3 / 4$ & $0 / 1$ & $1 / 1$ & $1 / 6$ & $0 / 1$ \\
R-NEN & $16 / 16$ & $2 / 4$ & $2 / 2$ & $4 / 4$ & $1 / 1$ & $1 / 1$ & $6 / 6$ & $1 / 1$ \\
R-NE* & $12 / 16$ & $1 / 4$ & $1 / 2$ & $3 / 4$ & $1 / 1$ & $1 / 1$ & $1 / 6$ & $0 / 1$ \\
E-BHT & $10 / 13$ & $1 / 4$ & $0 / 2$ & $3 / 4$ & $1 / 1$ & $1 / 1$ & $3 / 6$ & $0 / 1$ \\
E-ELI & $10 / 16$ & $2 / 4$ & $0 / 2$ & $2 / 4$ & $1 / 1$ & $1 / 1$ & $2 / 6$ & $0 / 1$ \\
E-PRO & $15 / 16$ & $3 / 4$ & $2 / 2$ & $3 / 4$ & $1 / 1$ & $1 / 1$ & $4 / 6$ & $0 / 1$ \\
E-PR* & $11 / 16$ & $3 / 4$ & $1 / 2$ & $2 / 4$ & $1 / 1$ & $0 / 1$ & $2 / 6$ & $0 / 1$ \\
E-WA & $15 / 16$ & $4 / 4$ & $2 / 2$ & $4 / 4$ & $1 / 1$ & $1 / 1$ & $1 / 6$ & $0 / 1$ \\
ANA & $16 / 16$ & $4 / 4$ & $2 / 2$ & $4 / 4$ & $1 / 1$ & $1 / 1$ & $3 / 6$ & $0 / 1$ \\
\hline
\end{tabular}

$W A=-11,40+3,58$ E-ELI). Trotz erheblich differierender Sensitivität und Spezifität der Testsysteme (Tab. 4) errechnet sich bei der Prävalenz in unserem Kollektiv eine vergleichbare diagnostische Effizienz. Die "Receiver Operation Characteristic" Kurven (Abb. 2) demonstrieren den Zusammenhang zwischen Sensitivität und Spezifität und unterstreichen die Bedeutung von Grenzwerten für die Interpretation der Ergebnisse.

\section{Diskussion}

Die Frage, welche labordiagnostischen Möglichkeiten man dem Kliniker in bezug auf die Bestimmung von antids-DNA-Antikörpern anbietet, läßt sich nicht leicht beantworten. Der ideale Test sollte im Hinblick auf die Laborroutine einfach und reproduzierbar sein, sensitiv, aber auch spezifisch, wenn möglich quantifizierbar und nicht allzu teuer.

In Labors, in denen die Bearbeitung von Mikrotiterplatten nicht automatisiert erfolgt, sind die ELISAs auf Pintechnikbasis und der Amersham-RIA, nicht zuletzt der kurzen Inkubationszeiten wegen, in der Handhabung am vorteilhaftesten. Allen Tests, außer dem E-BHT, liegt eine genügende Anzahl an Standards bei, und es sind sowohl positive als auch negative Kontrollseren erhältlich. Um die Standardisierung zu fördern, sind Assays zu bevorzugen, die sich an dem seit 1988 vorhandenen WHO-Standard Wo80 (4) orientieren. Dies ist bei allen der aufgeführten Tests mit Ausnahme des E-BHT und R-NEN der Fall. Die Listenpreise der in dieser Arbeit vorgestellten Assays gleichen sich in etwa. Hierzu kommen jedoch bei Radioimmunoassays die zusätzlich anfallenden Kosten für spezielle Radioaktivräume, Geräte und die Abfallentsorgung.

Ein Auswahlkriterium ist die Qualität des $A K$, den man erfassen möchte. Entsprechend dem RIA-Meßprinzip nach Farr werden Antikörper sämtlicher Immunglobulinklassen erfaßt. Durch die Verwendung von Ammoniumsulfat als Präzipitationsreagenz bei R-AB werden aufgrund der hohen Salzkonzentrationen Bindungen niedriger Avidität gelöst und somit die entsprechenden Antikörper nicht miterfaßt (10). Deshalb sind trotz der Standardisierung nach Wo80 unsere Ergebnisse z. B. im ELISA von Elias deutlich höher als im Amersham-RIA.

Das Spektrum der bestimmten Antikörperklassen ist je nach ELISA unterschiedlich; so erfassen zum Beispiel der Progen und Elias ELISA anti-ds-DNA-Antikörper der IgGKlasse, während der Walker ELISA die Antikörper der IgG- und IgM-Klasse und der ELISA von BHT sämtliche Klassen berücksichtigt. Bei 34 von 35 Patienten ergeben sich z. B. bei E-WA höhere Werte als bei E-ELI, was bei gleicher Standardisierung nach WHO (Wo 80) auf das Miterfassen von IgM anti-ds-DNA-Antikörpern zurückzu-
Tab. 4: Statistische Kenngrößen von verschiedenen Assays (Grenzwerte s. Tab. 1)

\begin{tabular}{lccccccc}
\hline & Prävalenz & $n$ & $\begin{array}{c}\text { Diagnost. } \\
\text { Sensitivität }\end{array}$ & $\begin{array}{c}\text { Diagnost. } \\
\text { Spezifität }\end{array}$ & $\begin{array}{c}\text { Diagnost. } \\
\text { Effizienz }\end{array}$ & $\begin{array}{c}\text { Vorhersagewert } \\
\text { positiver }\end{array}$ \\
negativer
\end{tabular}

führen sein dürfte. Bei allen Kits besteht die Möglichkeit, daß die Antikörper der Serumprobe nicht die gleiche Avidität wie das zur Standardisierung benutzte Material aufweisen. Solche Unterschiede führen zu einer nicht-linearen Dosis-Wirkungskurve, d. h. eine 1:2 Verdünnung des Patientenserums würde nicht die Hälfte des Meßsignals ergeben. Die intraindividuelle Verlaufsbeobachtung ist dennoch wertvoll und reproduzierbar. Bei dem Crithidia luciliae Assay kann man ebenfalls durch die Wahl des entsprechenden Konjugates die Klasse der erfaßten Antikörper bestimmen. Diese breite Palette an diagnostischen Möglichkeiten macht die individuelle Verlaufskontrolle des Patienten in verschiedenen Labors praktisch unmöglich. Beschrieben ist die Signifikanz der ds-DNA-Antikörper der IgG-Klasse für die Verlaufskontrolle. Ihr Anstieg zeigt eine bevorstehende Exazerbation der Erkrankung an $(14,17)$.

Wie aus Tabelle 1 hervorgeht, erfaßt man mittels der genannten Assays anti-ds-DNA-Antikörper nur bei einem Teil der Patienten mit SLE, andererseits gibt es positive Testergebnisse auch bei Patienten ohne gesicherten SLE. Eine Aufschlüsselung nach der Hauptdiagnose ist in Tabelle 3 enthalten. Anti-ds-DNA-Antikörper werden in etwa $50-75 \%$ bei SLE-Patienten in Abhängigkeit von Krankheitsaktivität und dem verwendeten Test nachgewiesen $(10,21)$. Bei längerfristiger Beobachtung sind sie bei ungefähr $90 \%$ der SLE-Patienten nachweisbar. Niedrigtitrige ds-DNA-Antikörper fand man unter anderem bei $\mathrm{Pa}$ tienten mit rheumatoider Arthritis, chronisch aktiver $\mathrm{He}-$ patitis, Sjögren Syndrom, medikamentös induziertem Lupus, Myasthenia gravis, Psoriasisarthritis, Uveitis und bei Patienten mit bestimmten Infektionskrankheiten ( $u$. a. Malaria, Schistosomiasis, Epstein Barr Virus Infektion) (10). Bei 5-15\% der Patienten mit klinischem SLE sind anti-ds-DNA-Antikörper nicht nachweisbar - bei einem Teil der Fälle wird die Bindung an Immunkomplexe angenommen (9). Auch in unserem relativ kleinen Kollektiv sind ds-DNA-Antikörper je nach Test bei etwa 62 bis $100 \%$ der SLE Patienten nachweisbar. Die Sensitivität des R-AB-Tests liegt mit $81 \%$ ähnlich wie in dem von Schmolke und Keratzopoulos untersuchten Kollektiv von 73 Patienten mit SLE (16).

Wie stark die Sensitivität und Spezifität eines Tests von den Herstellerangaben des cut-off-Wertes abhängig sind, zeigt das Beispiel des R-NEN (Tab. 1): so erfaßt R-NEN mit Grenzwert von $1 \mathrm{U} / \mathrm{ml} 16$ von 16 Lupuspatienten als positiv, allerdings werden auch 17 von 19 Patienten, die nicht an SLE leiden, als positiv eingestuft. Bei einem cutoff-Wert von $3,5 \mathrm{U} / \mathrm{ml}$ werden 12 der 16 SLE Patienten positiv, jedoch nur 8 von den 19 Lupus-negativen. Auf dieses Problem weisen auch die ROC.("receiver operation characteristic")-Kurven hin (Abb. 2). 
Eine mögliche Fehlerquelle bildet bei den ds-DNA-Assays die Reinheit der Antigenpräparation. Sollte die für den Test eingesetzte ds-DNA zusätzlich mit Proteinen verunreinigt sein, gegen die ein Patient Antikörper besitzt, so würden falsche Ergebnisse resultieren (2).

Im allgemeinen sind Antikörper gegen Einzelstrang DNA (ssDNA) gegen Purin- und Pyrimidinbasen-Polymere gerichtet, die nur bei den DNA Einzelsträngen zugänglich sind, nicht jedoch bei der helikal gefalteten dsDNA. Antikörper gegen ds-DNA erkennen hauptsächlich das Deoxyribosephosphat-Gerüst und reagieren deswegen sowohl mit Doppelstrang- als auch mit Einzelstrang-DNA. In einigen Fällen erkennen die Antikörper helikale ds-DNAStrukturen, die auch bei einer spontanen helikalen Anordnung von ss-DNA entstehen $(19,21)$. Ein bekanntes Problem bei RIAs ist die Bildung von ss-DNA durch Autoradiolyse. Besitzt nun ein Patient Antikörper gegen ssDNA, so werden durch das Miterfassen dieser falsch hohe anti-ds-DNA-Antikörperkonzentrationen : vorgetäuscht. Die Spezifität des Tests würde reduziert, da ssDNA-Antikörper bei einer Reihe von rheumatischen $\mathrm{Er}$ krankungen relativ häufig vorkommen (7). Diesem Problem versucht die Firma Amersham Buchler durch das Anbieten eines RIAs mit gentechnologisch hergestellter DNA als Antigen, mit weniger als $1 \%$ an EinzelstrangDNA, aus dem Wege zu gehen. Wegen der Gefahr des Miterfassens von ss-DNA-Antikörpern wurde in verschiedenen Labors den „alten” ds-DNA-RIAs der Crithidia luciliae Test parallel geschaltet, der lange Zeit für spezifisch, wenn auch nicht so sensitiv gehalten wurde (6). Einige $\mathrm{Li}$ teraturberichte $(3,5,8,11)$ weisen jedoch auch hier auf die Möglichkeit falsch positiver Resultate hin, über deren Ursache keine Einigkeit besteht. Um jedoch säureextrahierbare Antigene nicht zu erfassen, haben wir bei positiven Seren den Test nach der Objektträgerbehandlung mit 0,1 molarer $\mathrm{HCl}$ wiederholt.

Laut Henderson (5) wird durch die $\mathrm{HCl}$-Extraktion kein Einfluß auf die Spezifität und Sensitivität der Crithidia luciliae Untersuchung ausgeübt. Die von ihm beschriebene Quote falsch positiver Resultate ohne $\mathrm{HCl}$-Extraktion-beträgt $5 \%$ für SLE, $16 \%$ für medikamenteninduzierten LE und $5 \%$ für RA. Wie andere Labors (13) führen wir diese Objektträgerbehandlung routinemäßig durch, wobei bei den 35 untersuchten Seren 6 von 24 positiven nach der $\mathrm{HCl}$ Extraktion negativ beurteilt wurden.

Bei unserer Testung weist-der Crithidia luciliae Test mit einer diagnostischen Spezifität von 0,58 und einer Sensitivität von 0,63 eine ungünstigere diagnostische Effizienz als bei Rauterberg et al. (15) auf. Unter Verwendung desselben Assays wurde eine Spezifität von 0,91 und Sensitivität von 0,80 erreicht. Unsere Ergebnisse sind sicherlich auf die Auswahl des Patientengutes zurückzuführen (Tab. 3) - es sind immerhin jeweils zwei Patienten mit rheumatoider Arthritis und Sjögren Syndrom, je ein Patient mit MCTD, Sklerodermie, Borreliose und chronisch venöser Insuffizienz, die einen positiven Crithidia luciliae Test selbst nach der $\mathrm{HCl}$ Extraktion aufweisen. In Betracht zu ziehen wäre bei einigen von unseren Patienten ein beginnender SLE.

Zusammenfassend ist festzustellen, daß die diagnostische Effizienz (Tab. 4) der untersuchten Testsysteme zum Nachweis von anti-ds-DNA-Antikörpern in dem selektionierten Patientenkollektiv in etwa gleich zu bewerten ist. Neben der prinzipiellen Entscheidung für einen RIA oder ELISA wäre die Ermittlung der Spezifitäts-Sensitivitätsdiagramme des gewählten Assays hilfreich, um die Testergebnisse in Abhängigkeit vom eigenen Patientenprofil bestmöglich einordnen zu können. Die Kombination von einem anti-ds-DNA-ELISA oder RIA mit der ANA-IFT (12) und CLIF kann je nach Patientenkollektiv eine zusätzliche Sicherheit und Entscheidungshilfe bieten. Untersuchungen auf extrahierbare nukleäre Antigene (ENA) mittels der zur Zeit noch teuren ELISAs lassen eine höhere Nachweisempfindlichkeit als die etablierten Nachweisverfahren erwarten und dürften nach der erforderlichen laborchemischen und klinischen Evaluierung eine wertvolle Hilfe für die Differentialdiagnostik von Kollagenosen werden.

\section{Schrifttum:}

1. BABLOK, W., PASSING, H., BENDER, R., SCHNEIDER, B.: A general regression procedure for method transformation. Application of linear regression procedures for me thod comparison studies in clinical chemistry, Part. III. J. Clin. Chem. Clin. Biochem. 26, 783-790 (1988).

2. BRINET, A., FOURNEL, C., FALIRE, J. R., VENET, C., MONIER, J. C.: Anti-histon antibodies (ELISA and immunoblot) in canine lupus erythematosus. Clin. Exp. Immunol. 74(1), 105-109 (1988).

3. DENG, J. S., SONTHEIMER, R., LIPSCOMB, M. F., GILLIAM, N.: The binding of antihistone antibodies to Crithidia luciliae kinetoplasts is growth cycle dependent. Arthritis and Rheumatism 28(2), 163-168 (1985).

4. FELTKAMP, T. E., KIRKWOOD, T. B., MAINI, R. N., AARDEN, L. A.: The first international standard for antibodies to double stranded DNA: Ann. Rheum. Dis. 47(9), 740-746 (1988).

5. HENDERSON, T., MEDSGER, T. A., SONTHEIMER, R. D., HANNON, C. E., DENG, J. S.: Specificity of the hydrochloric-acid-modified Crithidia luciliae immunofluorescence as say for detection of antibody to native DNA. Diagn. Clin. Immunol. 5(1), 20-24 (1987). 6. ISENBERG, D. A DUDENY, C, WILLIAMS, W ADDISON I CHARLES, S CLARKE, J., TODD-POKROPEK, A.: Measurement of anti-DNA antibodies: a reappraisal using five different methods. Ann. Rheum. Dis. 46(6), 448-456 (1987).

7. JÄGER, L.: Immunologie. Gustav Fischer Verlag, Stuttgart (1990).

8. KONSTANTINOV, K. N., RUSSANOVA, V.: Evidence for absence of histones in the Crithidia luciliae kinetoplast: a study with anti-H2A and monoclonal anti-H3 antibodies: Br. J. Dermatol. 117, 451-456 (1987).

9. KRAPF, F. E., HERRMANN, M., LEITMANN, W., KALDEN, J. R.: Antibody binding of macromolecular DNA and RNA in the plasma of SLE patients. Clin. Exp. Immunol. 75, 336-342 (1989).

10. LAHITA, R. G.: Systemic Lupus Erythematosus. John Wiley \& Sons, New York (1987).

11. MCGUIGAN, L., EDMONDS, J., WELLINGS, G., JONES, M.: The significance of discrepant Farr and Crithidia luciliae tests. J. Rheumatol. 11(2), 172-174 (1984).

12. MILLER, M. H., LITTLEJOHN, G. O., JONES, B. W., STRNAD, H.: Clinical comparison of cultured human epithelial cells and rat liver as substrates for the fluorescent antinuclear antibody test. J. Rheumatol. 12(2), 265-269 (1985).

13. PAXTON, H., BENDELE, T., O'CONNOR, L., HAYNES, D. C.: Evaluation of the RheumaStrip ANA Profile test: a rapid test strip procedure for simultaneously determining antibodies to autoantigens U1-ribonucleoprotein (U1-RNP), SM, SS-ARo, SS-B/La and to native DNA. Clin. Chem. 36(5), 792-797 (1990).

14. PISETSKY, D. S., GRUDIER, J. P. GILKESON, G. S.: A role for immunogenic DNA in the pathogeneses of systemic Lupus erythematodes. Arthritis and Rheumatism 33(2) 153-159 (1990).

15. RAUTERBERG, E W. RAGUNATH, M. BRIDE, S., NEUMANN, I., ZIMMERMANN, G.: Der Crithidia lucilia Immunfluoreszenztest zum Nachweis von Autoantikörpern gegen Doppelstrang-DNS: Vergleich der diagnostischen Sensitivität und Spezifität von neun kommerziellen CLIF-Kits. Lab.med 13, 287-295 (1989).

16. SCHMOLKE, B., KERATZOPOULOS, D.: Erfahrungen mit einem standardisierten Testkit zur quantitativen Bestimmung von Doppelstrang-DNS-Antikörpern im Humanserum. Lab.med. 14, 363-367 (1990).

17. SEEUIG, H. P. Antikörper gegen Zellkernantigene. Fischer Verlag, Stuttgart (1983) 18. TALAL, N. Autoimmunity, Academic Press, New York-London (1977).

19. TAN, E. M. Antinuclear Antibodies: Diagnostic markers for autoimmune diseases 19. TAN, E. M.: Antinuclear Antibodies: Diagnostic markers for

and probes for cell biology. Adv. Immunol. 44, 93-151 (1989). 20. TAN, E. M., COHEN, A. S., FRIES, J. F., MASI, A. T., MCSHANE, D. J., ROTHFIELD,
N. F., SCHALLER, J. G., TALAL, N., WINCHESTER, R. J.: 1982 revised criteria for the classification of systemic lupus erythematosus. Arthritis Rheumatism 25(11), 1271-1277 (1982).

21. WALLACE, D. C., DUBOIS, E. L.: Dubois' Lupus Erythematodes, Lla \& Febiger, Third Edition, Philadelphia (1987).

\section{Danksagung:}

Die Autoren danken Frau B. Erle und Frau A. Niedermayer für die ausgezeichnete technische Assistenz.

Anschrift für die Verfasser:

Dr. M. Blazek

Med. Univ.-Klinik und Poliklinik

Zentrallabor

Bergheimerstraße 58

6900 . Heidelberg 